\title{
COMBINING THE ETHICS AND SCIENCE OF DISASTER MANAGEMENT: KEY ISSUES, POLICY CONSIDERATIONS AND BEST PRACTICES
}

\author{
Jason Levy \\ University of Hawaii, U.S.A. \\ E-mail: jlevy@hawaii.edu
}

Bishwajeet Pandey

Director Gyancity Research Lab.

E-mail: gyancity@gyancity.com

Recepción: 01/08/2019 Aceptación: 23/09/2019 Publicación: 06/11/2019

\section{Gitación sugerida:}

Levy, J. y Pandey, B. (2019). Combining the ethics and science of disaster management: key issues, policy considerations and best practices. 3C Tecnología. Glosas de innovación aplicadas a la pyme. Edición Especial, Noviembre 2019, 233-251. doi: http://dx.doi. org/10.17993/3ctecno.2019.specialissue3.233-251

\section{Suggested citation:}

Levy, J. \& Pandey, B. (2019). Combining the ethics and science of disaster management: key issues, policy considerations and best practices. 3C Tecnología. Glosas de innovación aplicadas a la pyme. Speciaal Issue, November 2019, 233-251. doi: http://dx.doi. org/10.17993/3ctecno.2019.specialissue3.233-251 


\section{ABSTRACT}

Around the world, the scientific discourse about disasters has historically focused predominantly upon the characteristics of the physical hazards themselves and the costs of mitigation actions to reduce the risks of these physical threats. While this physical science approach involves the expertise of talented experts from the fields of seismology, hydrology and geophysics the importance of addressing the root causes of disasters has become increasingly recognized in the social sciences. For example, in the broader public and policy literature, there are important ethical and social disaster issues which include understanding the root causes of community vulnerabilities and the ethical issues of not addressing climate change impacts (otherwise known as the costs of inaction). This research uses statistical tools including binary logistic regression to analyze ethical considerations in flood disaster management issues. Since many of Asia's worst floods have occurred in China they are used as a case study.

\section{KEYWORDS}

Disaster Management, Key Issues, Policy, Ethics and Science, Catastrophe. 


\section{INTRODUCTION}

Ethical decisions are key to shaping the disaster studies field and they must be included in the online classroom: It is important that values and ethical considerations are made explicit during the disaster planning process so that under conditions of pressure of urgency and criticality they can be made consistent with the ethical judgments that underlies the emergency management decision process. In the community disaster planning phase, there will be innumerable issues, each with its own ethical components. What humans and assets do we protect, and to what level of safety? How do we set disaster budgets and priorities? Answers explored during disaster preparedness activities should be based on key values and ethical analysis that can provide guidance during implementation Other issues include:

- How do we ensure that priority-setting judgments are not purely technical matters?

- How do we ensure the goals of transparency and accountability?

- Who should receive the most resources?

- Who do we rescue first?

- How do deal with families that refuse to follow mandatory evacuation orders?

- When do we stop expending resources to critically ill victims that are unlikely to survive?

- When do we phase out rescue efforts and shift to recovery mode?

The way these questions are answered reflects the ethical perspectives and moral analysis strategies of the planning group $(\mathrm{s})$. In this paper we consider the role of both ethical and scientific decisions in grave flood management challenges. Flood events often constitute a catastrophic disaster threat: they have an enormous impact on human wellbeing, jeopardizing important social development goals such as addressing poverty, ensuring adequate food, water, and sanitation, and protecting the environment. Direct losses from floods include drownings and injuries as well 
as damage to infrastructure and property, agricultural production, and sites of historical and cultural value. Indirect health problems often arise, such as waterborne infections, exposure to chemical pollutants released into flood waters, and vector-borne diseases.

\section{1998 YANGTZE RIVER FLOOD CASE STUDY}

At 6,300 km (3,900 miles) the Yangtze is Asia's longest river, the world's third longest and the most important waterway linking China's leading commercial hub, Shanghai, to the less industrialized regions of the Yangtze river basin: The fertile Yangtze River basin supports $40 \%$ of China's GDP (including $40 \%$ of the nation's agricultural and industrial output) and is home to one third of its people.. The Yangtze river basin is also a vital source of natural resources, accounting for $40 \%$ of China's freshwater resources, more than $70 \%$ of the country's rice and fishery production and half of its grain. The 1997-1998 El Nino and 1998 Asian summer monsoon was one of the strongest on record, and monsoon rains continued unabated for much of the summer. The central and southern parts of the country along the Yangtze river and its tributaries were severely impacted by more than 60 days of heavy flooding in the Yangtze River Valley. The Yangtze flooding constituted the world's single most devastating natural disaster in 1998 and China's worst flooding in over 40 years: approximately 200 million people were affected over 50 million acres as $670 \mathrm{~mm}$ of precipitation occurred in the Yangtze river valley from June to August, 1998 (Samel \& Liang, 2003). In July and August 1998, extensive flooding also occurred in northeast China, in the Songhuanjiang, Nenjiang and other rivers. The 1998 Yangtze floods affected more than 180 million people, killing approximately 4,000, damaging more than 10 million homes and forcing 14 million people to relocate. Direct economic losses were put at 31 billion US dollars.

Four factors which significantly worsened the impact of heavy rain during the 1998 flood were: 
- Deforestation and overgrazing, sharply reducing the capacity of forests and grasslands to retain water; Forest cover in Sichuan province fell from $20 \%$ of the land area in the 1950s to $9 \%$ by the late 1970s (Kirby, 2001).

- Loss of lakes and wetlands, cutting the capacity of the river's middle and lower reaches to store water. The surface area of the lakes along the Yangtze shrunk from 17,198 sq km in 1949 to only 6,605 sq km in 1980. In the early 1950s, the Yangtze basin had contained 4,033 large and small lakes, of which about 1,100 were lost over the past half century.

- Rising erosion rates, causing rivers and wetlands to fill with silt. For example, one of the largest reservoirs in Guangxi province, Changgang, has lost half a million cubic metres of capacity annually as it silts up.

- Snowmelt and melting glaciers in the Qinghai-Tibetan plateau.

Both the amount of precipitation over the Yangtze river catchment and the floodwater discharge from the upper basin of the Yangtze river did not exceed the historical extremes during the 1998 flooding, but water levels in the middle basin far exceeded the historical maximum. Historically, dikes have been built to control flooding along the Yangtze River, but the 1998 flood levels in the middle reaches of the Yangtze River forced Chinese officials to consider dramatic strategies to save large cities on the Yangtze River from inundation. During the summer of 1998, it was feared that Yangtze River flooding would cause the dikes along the Yangtze to fail to some degree, particularly those already weakened due to erosion, aging, or neglected repairs.

To minimize the probability of a catastrophic dike failure in the densely populated city of Wuhan (central China's largest industrial center, with more than 7 million residents in China's central Hubei province) and neighboring farmland, Chinese authorities deliberately destroyed dikes in Jianli County (Hubei province), about 90 miles upriver from Wuhan. This preventative action was successful in diverting floodwaters away from Wuhan, lowering the height of the Yangtze River at Wuhan. While this purposeful destruction of dikes at Jianli temporarily prevented Wuhan 
from being flooded, the social and economic impact on Jianli Country was immense: more than 500,000 people living adjacent to the Yangtze River were forced to evacuate (many on extremely short notice).

However, Chinese officials believed that saving Wuhan from inundation might also require opening floodgates and the deliberate destruction of dikes in the Jingiiang section of the Yangtze River which runs from Zhijiang (Hubei Province) to Chenglingji (Hunan Province). It is one of the most hazardous parts of the Yangtze River: the many bends in the river slow down the water and the riverbed is high due to the resulting sand and mud deposits. The higher water level in the Jingjiang leads to the ancient Chinese saying: "The danger of the Yangtze River lies in Jingjiang".

The $180 \mathrm{~km}$ Jingiiang river embankment provides defense for the central Chinese city of Wuhan and the major Beijing-Guanzhou Railway transportation artery. It also protects the productive 30,000 km2 Jianghan plain (an alluvial plain located in the middle and south of Hubei province which borders the Dongtinghu Plain and has an area of more than 30 thousand square kilometers).

The Jingjiang flood plain lies in central Hubei province which is home to over 300,000 people. The Jingiiang flood diversion area had not been used since 1954, when floods killed more than 30,000 people. However, purposefully destroying dikes at Jingiiang would reduce the risk of dikes suddenly bursting at Shashi City. Accordingly, extensive preparations were put in place to dynamite the Jingjiang dikes and divert waters into the Jingjiang floodplain. This was expected to submerge more than 1,000 square kilometers (386 square miles) of land and 27,000-33,000 ha (68,000-82,000 acres) of farmland in the Jingjiang floodplain. Deliberately flooding towns and villages in the Jingjiang area required the approval of the State Council of the People's Republic of China ((國務院), the chief administrative authority of the People's Republic of China. Since 1954 China's State Council has been constitutionally identical to the Central People's Government (Chinese: 中央人民政府), particularly in relation to local governments. China's state council is chaired by the Premier and includes the heads of each governmental department and agency. Currently, the council has 35 members: the premier, one executive vice premier, three vice premiers, five state 
councilors (of whom two are also ministers), and 25 additional ministers and chairs of major agencies.

In 1952 the Jingjiang Flood Diversion Project was undertaken in the northeastern part of the Gong'an County. Officials at the Jingjiang Flood Diversion Management Bureau were instructed to begin destroying dikes and opening floodgates when water levels on the Yangtze reached a record high of $45 \mathrm{~m}$ (149 feet) at the monitoring station in Shashi city, just north of the area that would be flooded. Fortunately, the water level at the Shashi monitoring station remained approximately $6 \mathrm{~cm}$ (2 in.) below the 45-m level. However, as a precautionary measure 330,000 people were evacuated from the Jingjiang region.

August 6, 1998: Hubai Provincial Flood Control Headquarters advised that there were critical flood levels. More than 300,000 people in the flood diversion area were evacuated to make room for diverted floodwaters

August 16, 1998: The water level in Shashi rose to 45.22 meters, which exceeded the 45.00 meter state stipulated flood diversion mark. However, in a bid to reduce losses, officials decided not to divert water.

August 20, 1998: The sixth Yangtze River crest threatened Wuhan and 2.3 million citizens and soldiers provided support for the Jingjiang River embankment.

However, in the summer of 1998 floods weakened the Jingjiang River embankment so 40,000 Chinese People's Liberation Army soldiers and half a million local citizens helped to withstand the floodwaters.

\section{YELLOW RIVER FLOOD WARFARE CASE STUDY}

The Imperial Japanese Army quickly obtained large swaths of Chinese territory at the onset of the Second Sino-Japanese War in 1937 and by June 1938, the Japanese had control of all of North China. On June 6, 1938 the Japanese imperial army captured Kaifeng, the capital of Henan, and threatened to take over Zhengzhou which would have directly endangered the major Chinese cities of Wuhan and Xi'an 
(as Zhengzhou stood at the junction of the critical Pinghan and Longhai Railways). To deter further Japanese advances into western and southern China, the Chinese Nationalist leader General Chiang Kai-shek opened the dikes on the Yellow River near Zhengzhou on the advice of Chen Guofu, a prominent political ally in party affairs. Specifically, the dike was destroyed on June 5, 1938 and June 7, 1938 at Huayuankou, on the south bank of the Yellow River causing flooding in the Eastern states of Henan, Anhui, and Jiangsu.

The deliberate floods constitute what many consider to be the largest war induced environmental disaster in history (Dutch, 2009; Lary, 2004). This act of environmental warfare destroyed thousands of square kilometers of farmland and shifted the mouth of the Yellow River hundreds of miles south. It is estimated that the disaster affected approximately five million people. In particular, the flood inundated thousands of villages, thereby driving villagers from their homes and creating three million refugees. It is estimated that at least 400,000-500,000 died from the flooding with another half a million becoming homeless. Besides this large death toll, the ecological toll on agricultural and other ecological resources was severe: crops in the abandoned, flooded countryside were destroyed and irrigation channels were ruined. Moreover, even once the water eventually receded the soil was often uncultivable as much of the land was covered in silt. Both private property and public infrastructure were destroyed, leaving survivors destitute. 


\section{ANALYSIS TOOLS FOR UNDERSTANDING ETHICAL AND SCIENTIFIC DIMENSIONS}
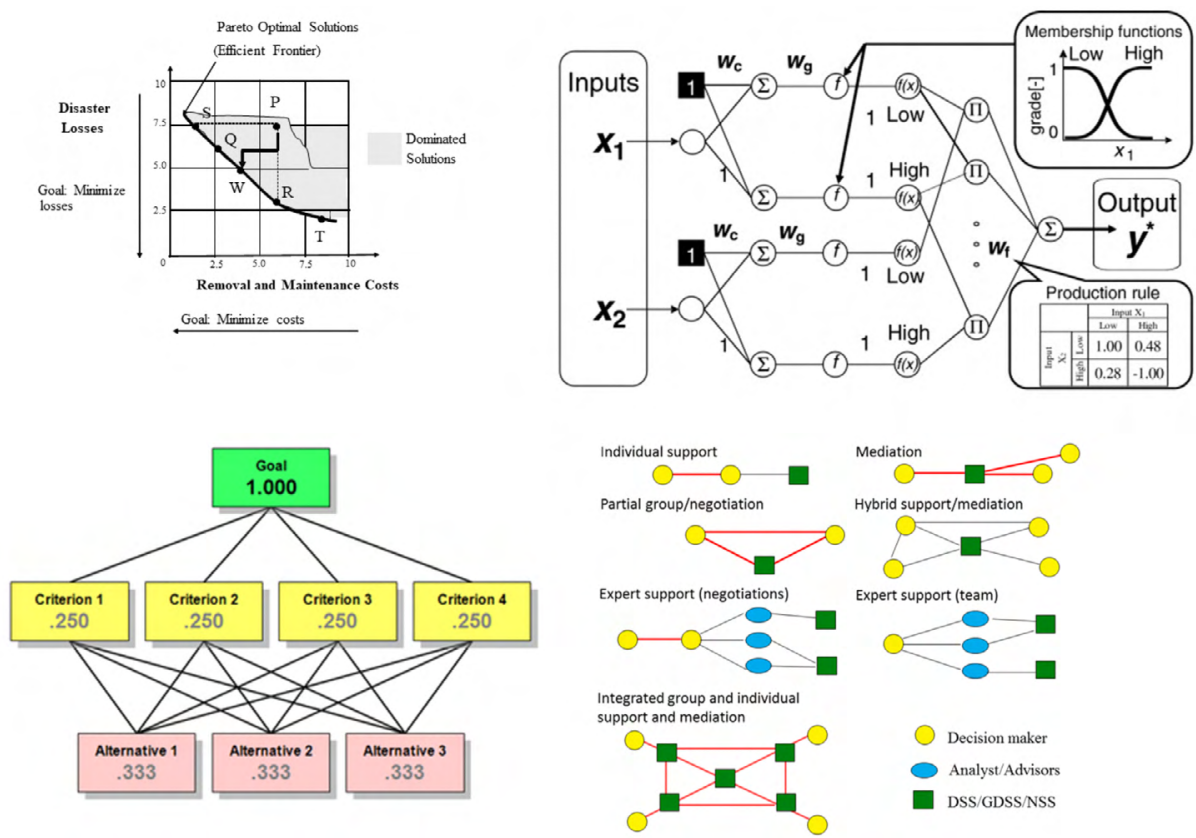

Figure 1. Analysis tools for combing the science and ethics of disaster management.

A wide number of tools have been proposed for integrating the science and ethics of disaster management, as shown in Figure 1 including group decision analysis and soft computing approaches including fuzzy-neural analysis. Discriminant function analysis (DFA) is typically employed in the presence of a categorical dependent variable if all of the predictors are continuous and nicely distributed about the mean. It is used primarily to predict group membership from a set of continuous predictors. Specifically, DFA assumes multivariate normality, i.e. the means of the various Dependent Variables (DVs) in each cell and all linear combinations of the DVs are normally distributed. On the other hand, Logit analysis is usually employed if all the predictors are categorical.

Logistic regression is used to predict a categorical (usually dichotomous) variable from a set of predictor variables where the predictor variables are a mix of continuous and categorical variables and/or if they are not nicely distributed. The medical 
community often uses logistic regression for problems in which the dependent variable is whether or not a patient has a disease.

For a logistic regression, the predicted dependent variable is a function of the probability that a particular individual will be in one of the categories (i.e. that an individual has a disease, given her set of scores on the predictor variables).

As an example of the use of logistic regression in disaster research consider the Yangtze River flood case study. Disaster management college students in India and USA $(\mathcal{N}=630)$ were asked to pretend that they were serving as a member of the State Council of the People's Republic of China hearing arguments for and against the destruction of dikes at Jianli and Jingiiang. The discussion included a description of the emergency management options in logical but emotional language. Various points of view were put forth and computer simulations were carried out to show the impact of the proposed evacuations and dam breaches on communities. Each participant read one of five different scenarios which described the goals and benefits of the proposed dam breaches. They were:

- ECONOMIC-protecting down-stream economic assets including the central Chinese city of Wuhan and the major Beijing-Guangzhou Railway transportation artery.

- ENVIRONMENTAL-the need to protect the productive Jianghan plain.

- SOCIAL-the challenges associated with evacuation and the threats to life safety associated with flooding.

- POLITICAL-understanding the decision making process in China's state council and the Jingjiang Flood Diversion Management Bureau.

- MILITARY-camouflaged soldiers reinforced the earthen dikes along the banks of the Yangtze river in order to help back the swollen river. With waters on the Yangtze at their highest levels in 44 years, nearly 5 million people in five provinces were mobilized to help fortify the embankments. 
After reading the background of the Yangtze River flooding and the other case materials, each student was asked whether or not to proceed with the study. Participating students were asked to fill out an Ethics Position Questionnaire (EPQ) (Forsyth, 1980) which assesses personal moral philosophy. The instrument contains two dimensions: relativism and idealism. Scoring high on the relativism subscale of the EQP is consistent with a personal and situational moral philosophy and a rejection of universal moral principles. Overall, high scorers on the idealism subscale of the EQP espouse a concern for the welfare of others and believe that ethical behavior leads only to positive outcomes, never to bad or mixed consequences (Forsyth, Nye, \& Kelley, 1985).

The EPQ asks questions about acceptance of issues that vary in terms of relativism and idealism. The instrument contains 20 Likert-type items (each with a 9-point response scale from "completely disagree" to "completely agree"). The relativism scale includes items such as "Different types of moralities cannot be compared as to "rightness" and "What is ethical varies from one situation to another." The idealism scale, in contrast, measures one's perspective on positive and negative consequences with such items as "A person should make certain that their actions never intentionally harm another even to a small degree" and "If an action could harm an innocent other than it should not be done" (Forsyth, 1980). It is important to note that idealists (persons who score high on the idealism dimension) do not make ethical decisions by balancing good consequences against negative outcomes; rather, for an idealist, the existence of any negative outcomes may make a behavior unethical, even though there may be many positive consequences.

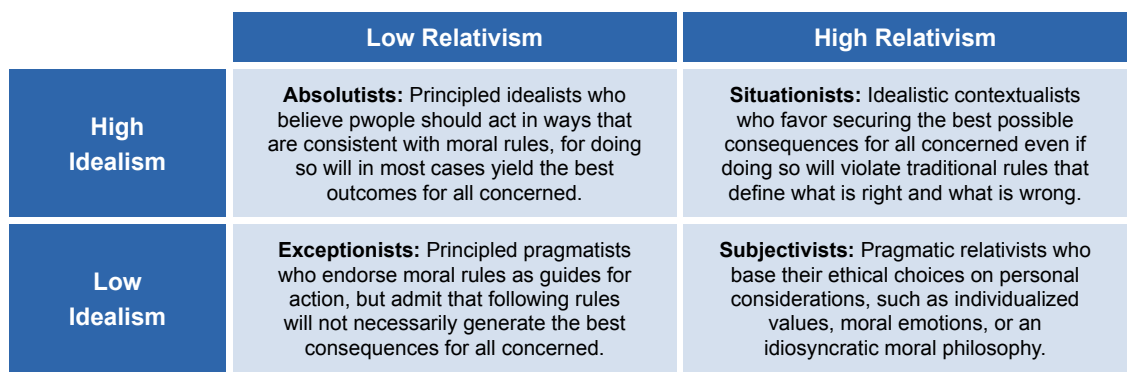

Figure 2. Four-fold classification of Personal Moralities based on Idealism and Relativism. Source: (Forsyth, 1980). 
A four-fold classification based on Idealism and Relativism is shown in Figure 2. There are four quadrants that categorize various individuals on the basis of their personal moral philosophy and ethical choices: Situationalists, Absolutists, Exceptionalists and Subjectivists. Situationalists are highly relativistic and idealistic contextualists: they believe that individuals should seek to achieve the best outcomes possible, but that moral rules cannot be universally applied across all situations: adherents prescribe close examination of individual situation in reaching a contextually appropriate moral evaluation. Absolutists, like Situationists, are also idealistic; they support decisions that yield positive, desirable consequences. However, Absolutists are not relativistic; they believe that ethical absolutes must be included in any code of ethics.

Subjectivists and Exceptionalists are both low in terms of idealism. Subjectivists are pragmatic relativists that reject universal moral rules (high relativism) and believe that following rules will not necessarily lead to the best outcomes for all concerned (less idealistic about the possibility of achieving humanitarian goals). Its adherents make subjective, individualistic moral judgments rather than basing their ethical choices on more "objective" information, such as universal moral absolutes or the extent to which a given action harms others. Finally, Exceptionists are principled pragmatists who endorse moral rules as guides for behavior but believe that following actions that lead to some negative consequences shouldn't necessarily be dismissed. Low in both relativism and idealism they are willing to make exceptions to their moral principles. Human and animal rights activists tend to be high in idealism and low in relativism. This study examines whether gender, idealism and relativism are related towards attitudes in complex emergency management decisions.

\section{LOGISTIC REGRESSION ANALYSIS}

We begin with a simple bivariate logistic regression, using student's decisions as the dichotomous criterion variable and gender as a dichotomous predictor variable where we have coded gender with $0=$ Female, $1=$ Male and decision with $0=$ stop the decision to breach the dam and $1=$ continue with the decision to breach the dam. 
Our regression model involves predicting the logit, i.e. the natural log of the odds of have made one or the other decision. That is:

$$
\ln (\text { odd } s)=\ln \left(\frac{\hat{y}}{1-\hat{y}}\right)=a+b X
$$

where $\hat{y}$ is the predicted probability of the event which is coded with 1 (continue with the plans to destroy the dykes and open the floodgates) rather than 0 (not to proceed with dynamiting the dykes and opening the floodgates). $1-\hat{y}$ is the predicted probability of the other decision and $\mathrm{X}$ is the predictor variable, gender. The intercept (constant term) is given by $a$ and $b$ is the slope from the logistic regression equation.

An iterative maximum likelihood procedure is used to construct a logistic regression model. Starting with an arbitrary value of the regression coefficients an initial model for predicting the observed data is constructed. Errors in the aforementioned prediction are then evaluated and the regression coefficients are changed in order to make the likelihood of the observed data greater under the new model. The procedure is iterative since the procedure repeats until the differences between the latest model and the previous model are trivial (i.e. the model converges).

Observing the statistical output we observe that 630 cases are used in the analysis (Figure 1).

Table 1. Case Processing Summary.

\begin{tabular}{|c|c|c|c|}
\hline \multicolumn{3}{|c|}{ Case Processing Summary $^{*}$} & \\
\hline Unweighted Cases & \\
\hline \multirow{2}{*}{ Selected Cases } & Included in Analysis & 630 & 100.0 \\
\hline & Missing Cases & 0 & .0 \\
\hline & Total & 630 & 100.0 \\
\hline Unselected Cases & 0 & .0 \\
\hline & Total & 630 & 100.0 \\
\hline
\end{tabular}

Block 0 output is for a model that includes only the intercept (constant term). Given the base rates of the two decision options $58.4 \%$ (i.e. 368/630) of students decided to stop the dam destruction implementation while $41.6 \%$ decided to allow it to continue (Table 2). Without any other information the best statistical inference is to predict, 
for every case, that the student will decide to stop the dam destruction. Using that strategy one would be correct $58.4 \%$ of the time.

Table 2. Classification Table.

\begin{tabular}{|c|c|c|c|c|c|}
\hline \multicolumn{6}{|c|}{ Classification Table ${ }^{a, b}$} \\
\hline & \multirow[t]{3}{*}{ Observed } & & \multicolumn{3}{|c|}{ Predicted } \\
\hline & & \multicolumn{2}{|c|}{ Decision } & \multirow{2}{*}{\multicolumn{2}{|c|}{ Percentage Correct }} \\
\hline & & Stop & Continue & & \\
\hline \multirow{3}{*}{ Step 0} & \multirow{2}{*}{ Decision } & Stop & 368 & 0 & 100.0 \\
\hline & & Continue & 262 & 0 & .0 \\
\hline & \multicolumn{2}{|c|}{ Overall Percentage } & & & 58.4 \\
\hline \multicolumn{6}{|c|}{ a. Constant is included in the model. } \\
\hline \multicolumn{6}{|c|}{ b. The cut value is .500} \\
\hline
\end{tabular}

Table 3 (variables in the equation) shows that the intercept only model is:

$\ln ($ odds $)=-0.340$ which yields the predicted odds is $[\operatorname{Exp}(\mathrm{B})]=0.711$. That is, the predicted odds of deciding to continue with the dyke destruction is 0.711 . Since 262 of the students decided to continue the dyke destruction and 368 decided to stop the destruction, our observed odds are 262/368 $=0.712$.

Table 3. Variables in the Equation.

\begin{tabular}{|c|c|c|c|c|c|c|c|}
\hline \multicolumn{8}{|c|}{ Variables in the Equation } \\
\hline & & B & S.E. & Wald & df & Sig. & $\operatorname{Exp}(B)$ \\
\hline Step 0 & Constant & -.340 & .081 & 17.664 & 1 & .000 & .712 \\
\hline
\end{tabular}

Now look at Block 1 output where the gender variable is added as a predictor. The Omnibus Test of Model Coefficients (Table 4) illustrates a Chi-square of 48.198 on 1 $d f$, significant beyond .001 . This is a test of the null hypothesis that adding the gender variable to the model has significantly increased our ability to predict decisions made by the students. The -2 Log likelihood statistic (807.247) models how well the model predicts the decisions (the smaller the better) as shown in the model summary (Table 5). The Cox and Snell $R^{2}(0.074)$ is like the interpretation of $R^{2}$ in multiple regression, but does not reach a maximum value of 1 , whereas the Nagelkerke $R^{2}$ can reach a maximum of 1 . 
Table 4. Omnibus Tests of Model Coefficients.

\begin{tabular}{|c|c|c|c|c|}
\hline \multicolumn{5}{|c|}{ Omnibus Tests of Model Coefficients } \\
\hline \multirow{2}{*}{ Step 1 } & Step & 48.198 & df & Sig. \\
\hline & Block & 48.198 & 1 & .000 \\
\hline & Model & 48.198 & 1 & .000 \\
\hline
\end{tabular}

Table 5. Model Summary.

\begin{tabular}{|c|c|c|c|}
\hline \multicolumn{4}{|c|}{ Model Summary } \\
\hline Step 1 & $\begin{array}{c}-\mathbf{2} \text { Log } \\
\text { likelihood }\end{array}$ & $\begin{array}{c}\text { Cox \& Snell R } \\
\text { Square }\end{array}$ & $\begin{array}{c}\text { Nagelkerke R } \\
\text { Square }\end{array}$ \\
\hline & $807.247^{\text {a }}$ & .074 & .099 \\
\hline \multicolumn{2}{|c|}{ a. Estimation terminated at iteration number 3 because parameter estimates } \\
changed by less than .001.
\end{tabular}

\section{ANALYSIS}

The Variables in the Equation output (Table 6) shows us that the regression equation is $\ln ($ odds $)=-.788+1.176$ Gender. We can now use this model to predict the odds that a subject of a given gender will decide to continue with the dyke destruction. When the student is a woman (gender $=0$ ), then odd $s=e^{-0.788+1.176(0)}=e^{-0.788}=0.455$. That is, a female student is only 0.455 as likely to approve the dyke destruction as she is to stop the destruction. For male students $\left(\right.$ gender $=1$ ) then odds $=e^{-0.788+1.176(1)}=e^{0.388}=1.474$. That is, a male student is 1.474 times more likely to decide to continue the dyke destruction as she is to stop the destruction.

The odds are now converted to probabilities. For women students in the study

$$
\hat{y}=\frac{o d d s}{1+o d d s}=\frac{0.455}{1+0.455}=0.31
$$

That is the model predicts that $31 \%$ of women will decide to continue to destroy the dykes. For men: 


$$
\hat{y}=\frac{o d d s}{1+o d d s}=\frac{1.474}{1+1.474}=0.60
$$

That is our model predicts that $60 \%$ of men will decide to continue to destroy the dykes.

The variables in Equation output (Table 6) provides the odds ratio predicted by the model: $\operatorname{Exp}(\mathbf{B})$ provided in the right most column. The odds ratio is obtained by raising the base of the natural $\log$ to the $b^{\text {th }}$ power, where $b$ is the slope from the logistic regression equation. In our model the result is $e^{1.176}=3.241$ which means that the model predicts the odds of deciding to continue the dam destruction are 3.241 times higher for men than they are for women. For men, the odds are 1.474, and for women they are 0.455 . The odds ratio is: $1.474 / 0.455=3.24$.

Table 6. Variables in the Equation.

\begin{tabular}{|c|c|c|c|c|c|c|c|}
\hline \multicolumn{8}{|c|}{ Variables in the Equation } \\
\hline \multirow{3}{*}{ Step 1 1} & B & S.E. & Wald & df & Sig. & Exp(B) \\
\cline { 2 - 9 } & Conder & 1.176 & .172 & 46.570 & 1 & .000 & 3.241 \\
\hline & Constant & -.788 & .108 & 53.424 & 1 & .000 & .455 \\
\hline & a. Variable(s) entered on step 1: gender. \\
\hline
\end{tabular}

In order to classify subjects according to their decision we establish the following decision rule: If the probability of the event is greater than or equal to 0.5 (the SPSS threshold set by default), then it is predicted that the event will take place (in some cases we may wish to set the threshold higher or lower than 0.5). Using the 0.5 threshold we classify a student into the "Continue with Dam Destruction" category if the estimated probability is more than 0.5 , which it is for every male student. A subject is classified into the "Stop the Dam Destruction" category if the estimated probability is less than 0.5 which it is for every female student.

The sensitivity of the prediction, i.e. the percentage of occurrences correctly predicted is now examined: $P$ (correct|event occurred). For the "Continue with Dam Destruction" event the Classification Table (Table 7) shows us that this rule allows us to correctly classify $137 /(125+137)=52.3 \%$ of the subjects where the 
predicted event was observed. For the specificity of the prediction, i.e. the percentage of nonoccurrence's correctly predicted we have: $P$ (correct|event did not occur) $=275 /(275+93)=74.7 \%$. Hence this rule correctly classifies $74.7 \%$ of the subjects where the predicted event did not occur (i.e. "Stop Dam Destruction"). Overall the predictions were correct 412 (i.e. $275+137$ ) out of 630 times for an overall success rate of $65.4 \%$. Recall that the overall success rate was $58.4 \%$ for the model with the intercept only.

Table 7. Classification Table.

\begin{tabular}{|c|c|c|c|c|c|}
\hline \multicolumn{6}{|c|}{ Classification Table } \\
\hline \multirow{5}{*}{ Step 1} & \multicolumn{2}{|c|}{ Observed } & \multicolumn{3}{|c|}{ Predicted } \\
\hline & \multirow{3}{*}{ Decision } & \multirow{2}{*}{$\begin{array}{l}\text { Stop } \\
\text { Stop }\end{array}$} & \multirow{2}{*}{$\begin{array}{c}\text { Continue } \\
275\end{array}$} & \multicolumn{2}{|c|}{ Percentage Correct } \\
\hline & & & & 93 & 74.7 \\
\hline & & Continue & 125 & 137 & 52.3 \\
\hline & \multicolumn{2}{|c|}{ Overall Percentage } & & & 65.4 \\
\hline \multicolumn{6}{|c|}{ a. The cut value is .500} \\
\hline
\end{tabular}

\section{CONCLUSIONS}

A wide number of tools are herein proposed for integrating the science and ethics of disaster management. These include group decision analysis and soft computing approaches including evolutionary algorithms and fuzzy-neural analyses. Discriminant function analysis (DFA) is typically employed in the presence of a categorical dependent variable if all of the predictors are continuous and uniformly distributed about the mean. On the other hand, Logit analysis is usually employed if all of the predictors are categorical It is shown that males are 1.474 times more likely to decide to continue dyke destruction and sacrifice human lives than females.

Ethical decisions are key to shaping the disaster studies field and they must be included in a formal disaster policy analysis: It is important that values and ethical considerations are made explicit during the disaster planning process so that under conditions of pressure of urgency and criticality they can be made consistent with the ethical judgments that underlies the emergency management decision process. It is 
concluded that in the community disaster planning phase, there will be innumerable issues, each with its own ethical components. What humans and assets do we protect, and to what level of safety? How do we set disaster budgets and priorities?

\section{REFERENCES}

Dutch, S. I. (2009). The Largest Act of Environmental Warfare in History. Environmental E Engineering Geoscience, 15(4), 287-297. doi: https://doi.org/10.2113/ gseegeosci.15.4.287

Forsyth, D. R. (1980). A taxonomy of ethical ideologies. Fournal of Personality and Social psychology, 39(1), 175.

Forsyth, D. R., Nye, J. L., \& Kelley, K. (1988). Idealism, relativism, and the ethic of caring. The fournal of Psychology, 122(3), 243-248.

Kirby, A. (2001). Plan to tame Yangtze floods. Retrieved from: http:/ / news.bbc.co.uk/2/ hi/science/nature/1595327.stm

Lary, D. (2004). The Waters Covered the Earth: China's War-Induced Natural Disaster. In Mark Selden and Alvin Y. So, ed. War and State Terrorism: The United States, Japan, and the Asia-Pacific in the Long Twentieth Century. Rowman \& Littlefield, 143-170.

Muscolino, M. S. (2014). The Ecology of War in China: Henan Province, the Yellow River, and Beyond, 1938-1950. Cambridge University Press.

Samel, A. N., \& Liang, X. Z. (2003). Understanding relationships between the 1998 Yangtze River flood and northeast Eurasian blocking. Climate Research, 23(2), 149-158. 
Edición Especial Special Issue Noviembre 2019

DOI: http://dx.doi.org/10.17993/3ctecno.2019.specialissue3.233-251 